3 Carter D. Margins of "lumpectomy" for breast cancer. Hum Pathol 1986;17:330-2.

4 Paterson DA, Davies JD. A cobalt aluminate method of marking resection margins. $J$ Pathol 1987;152:206A-7A.

\section{Congenital malaria in one identical twin}

Congenital malaria is rare in Britain. We report uniovular twins, only one of whom developed congenital Plasmodium vivax infection.

A healthy primigravid woman delivered full term twins four months after her arrival in England from India. The delivery was normal, and the placenta was undamaged and consistent with a monozygotic pregnancy. Haemoglobin estimations at birth suggested a twin-to-twin transfusion $(18.0 \mathrm{~g} / \mathrm{dl}$ and 26.5 $\mathrm{g} / \mathrm{dl}$ for twins I and II, respectively). Twin II therefore had one third of her blood volume exchanged with plasma protein fraction; thereafter her progress was uneventful.

When reviewed one month later, the mother and both twins had no fever and physical examination showed no abnormal physical signs. Repeat estimates of haemoglobin concentration were $7.5 \mathrm{~g} / \mathrm{dl}$ (twin I) and $13.0 \mathrm{~g} / \mathrm{dl}$ (twin II). Trophozoites and gametocytes of Plasmodium vivax were observed on the blood film of twin I (parasitaemia $0.3 \%$ ) but not in repeated thick and thin blood films from Twin II. Scanty infestation with Plasmodium vivax was also present in the mother (thick film only). (These findings were later confirmed by the Malaria Reference Laboratory at the Hospital for Tropical Medicine and Hygiene.) IgM antimalarial antibodies were detected in serum from twin I but not from twin II (table), consistent with congenital infection in the former; IgG antibodies, presumably of transplacental origin, were present in both. Chloroquine was administered to the mother and both twins (10 mg base $/ \mathrm{kg}$ initially, repeated after six hours, and then daily for five days), and all three were well when reviewed three months later.

Since 1980 , less than 20 cases of congenitally acquired malaria have been reported in Britain. A case of congenital malaria has previously been described in the second-born of non-identical twins ${ }^{1}$; premature placental separation was implicated. We believe ours to be the first reported case of congenital malaria in one of a pair of identical twins. As both twins were probably exposed to Plasmodium vivax during birth, the exchange transfusion of the second twin may have removed infected erythrocytes and thus protected against the development of clinically important parasitaemia. It seemed reasonable to suppose that both twins could be infected,

Malarial immunofluorescent antibody test reactions in two identical twin

\begin{tabular}{lll}
\hline & Twin I & Twin II \\
\hline IgG & ++++ & +++ \\
IgM & +++ & -
\end{tabular}

Reactions were graded visually from absent $(-)$ to Reactions were graded visually from absent $(-)$ to very strong $(++++)$. The
was from Plasmodium fieldi. however, and so both were treated. As congenitally acquired malaria does not involve passage of sporozoites, an exoerythrocytic cycle does not occur. Chloroquine alone was therefore the treatment of choice. ${ }^{12}$

$$
\begin{array}{r}
\text { D CUMMINS } \\
\text { C BRAIN } \\
\text { SC DAVIES } \\
\text { Haematology and Paediatric Departments, } \\
\text { Central Middlesex Hospital, } \\
\text { Acton Lane, London NW10 } 7 N S
\end{array}
$$

1 Bradbury AJ. Congenital malaria in one nonidentical twin. Br Med J 1977;2:613.

2 Quinn TC, Jacobs RF, Mertz GJ, Hook EW

Locklsey RM. Congenital malaria: A report of four cases and a review. $J$ Pediatr 1982;101:229-32.

\section{Survival of Helicobacter pylori in water} and saline

Helicobacter (Campylobacter) pylori is a ubiquitous human parasite and the most common and important cause of gastritis. The natural reservoir for this organism is probably the human stomach, but the mode of transmission from person to person remains unknown. Although $H$ pylori has never been isolated from an environmental source, recent studies ${ }^{2}$ have shown that, like Campylobacter jejuni, ${ }^{3}$ it may survive in fresh water microcosms in a viable state for more than 10 days and as viable, non-culturable coccoid bodies for up to one year.

We studied the survival of $H$ pylori (NCTC) 11916) in sterile distilled water, physiological saline, and artificial seawater. ${ }^{4}$ Viable counts were determined using a standard microbiological dilution method, with inoculation on to a selective isolation medium for campylobacters (modified New York City medium). Plates were incubated under microaerophilic conditions at $37^{\circ} \mathrm{C}$ for three to four days. Colonies were counted and expressed as colony forming units per millilitre $(\mathrm{cfu} / \mathrm{ml})$ and also tested for rapid urease, oxidase, catalase, and Gram reactions to confirm the identity of surviving organisms. Counts were repeated at daily intervals from suspensions stored at room temperature and at $7^{\circ} \mathrm{C}$ in the dark. Experiments were performed in duplicate.

At $7^{\circ} \mathrm{C}, H$ pylori (NCTC 11916 ) remained viable for culture when suspended in distilled water for a period of between 11-14 days, saline for 16 days, and artificial seawater for between three and seven days (figure). Suspensions stored at room temperature, however, became non-culturable within one day of inoculation in distilled water and seawater, and within three days in physiological saline. Similar results were found with $H$ pylori (NCTC 11639) and a recently isolated strain.

The non-culturable bacterial suspensions contained coccoid forms of the organism, which have been shown to be viable. ${ }^{2}$ Coccoid cells of $C$ jejuni may be transformed into culturable, spiral forms by animal passage. ${ }^{3}$ Water borne outbreaks of campylobacteriosis have been described, ${ }^{3}$ and urease positive campylobacters have been isolated from the roots of aquatic plants, from freshwater and seawater. $^{5}$

AP WEST
MR MILLAR
Department of Microbiology,
University of Leeds,
Leeds LS2 $9 J T$
DS TOMPKINS
Department of Microbiology,
Bradford Royal Infirmary,
Bradford BD $6 \mathrm{RJ}$

1 Graham DY. Campylobacter pylori and peptic ulcer disease. Gastroenterology 1989;96: 615-25.

2 Shahamat M, Paszko-Kolva C, Yamamoto $H$ Mia U, Pearson AD, Colwell RR. Ecological studies of Campylobacter pylori. Klin Wochenschr 1989;67(Supp XVIII):62-3.

3 Rollins DM, Colwell RR. Viable but non-culturable stage of Campylobacter jejuni and its role in survival in the natural aquatic environ ment. Appl Environ Microbiol 1989;52:531-8.

4 Dawson RMC, Elliot DC, Elliot WH, Jones KM. Data for biochemical research edition). Oxford: Oxford University Press, 1969:508.

5 Bolton FJ, Holt AV, Hutchinson DN. Ureasepositive thermophilic campylobacters. Lance positive thermo $1985 ; \mathbf{i}: 1217-8$.

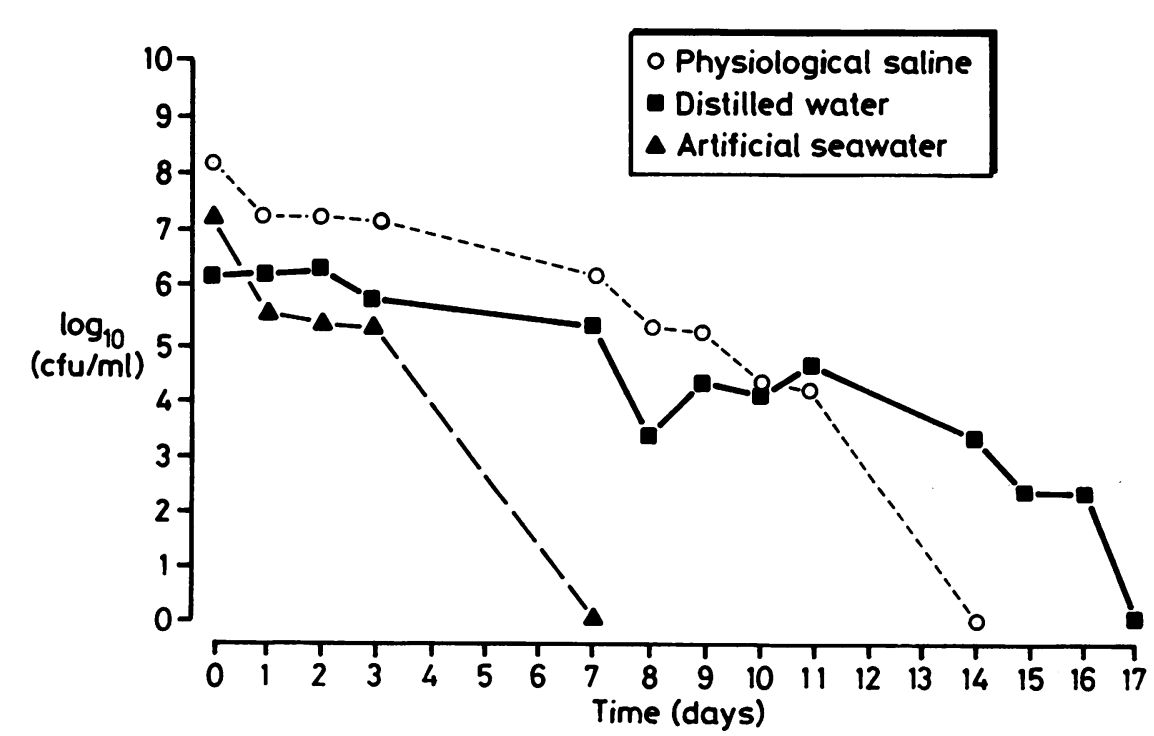

Survival of H pÿlori (NCTC 11916) in distilled water, physiological saline, and artificial seawater at $7^{\circ}$. 